\title{
JOURNAL.RU
}

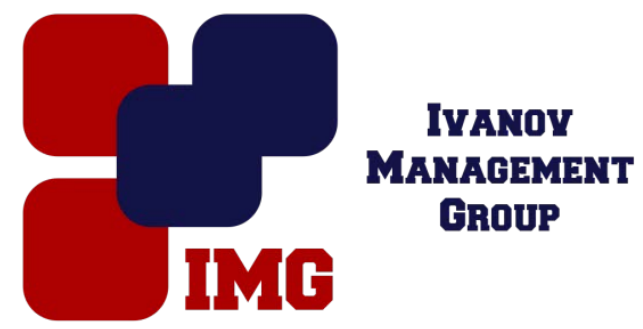

Маслов Л.Н., Маслов М.Л., Сунцов Е.В. Ижевский государственный технический университет имени М.Т. Калашникова Ижевск, Россия

doi: 10.18411/lj-28-02-2017-1-09

idsp 000001:lj-28-02-2017-1-09

\section{Технология высокотемпературной упрочняюще-калибрующей термомеханической обработки - резерв снижения трудоемкости изготовления изделий отечественного машиностроения}

Технология термомеханического упрочнения как метод повышения механических свойств металлопродукции и эксплуатационных характеристик различных тяжелонагруженных деталей машин достаточно известна [1,2]. Однако, промышленное использование стальной металлопродукции после термомеханической обработки (ТМО) для изготовления деталей машин ограничено в связи со сложностями обработки резанием стали в высокопрочном состоянии из-за высокой твердости. Поэтому большое внимание в ряде работ последних десятилетий в области ТМО уделяется повышению точностных характеристик упрочненной с применением этого метода металлопродукции и выпуска еe в виде проволоки и калиброванной стали, позволяющих при изготовлении ряда деталей минимизировать или, для деталей простой геометрической формы, полностью исключить обработку резанием и, только в качестве финишных операций, применять абразивную обработку.

Другим вариантом снижения объема дополнительной обработки резанием и одновременного повышения эксплуатационной надежности изделий машиностроения является «встраивание» в базовый технологический процесс изготовления детали операций термомеханического упрочнения и калибровки необходимых поверхностей. Другими словами, задача для осуществления этого варианта состоит в создании технологии и оборудования для производства высокоточных упрочненных заготовок деталей машин конкретного назначения с учетом условий их эксплуатации [3,4].

В Ижевском государственном техническом университете имени М.T. Калашникова разработаны технология и оборудование для производства калиброванной проволоки и калиброванной стали с применением высокотемпературной упрочняюще-калибрующей термомеханической обработки (ВУК ТМО). Схемы установок для осуществления этого процесса приведены на рисунках 1 и 2. 


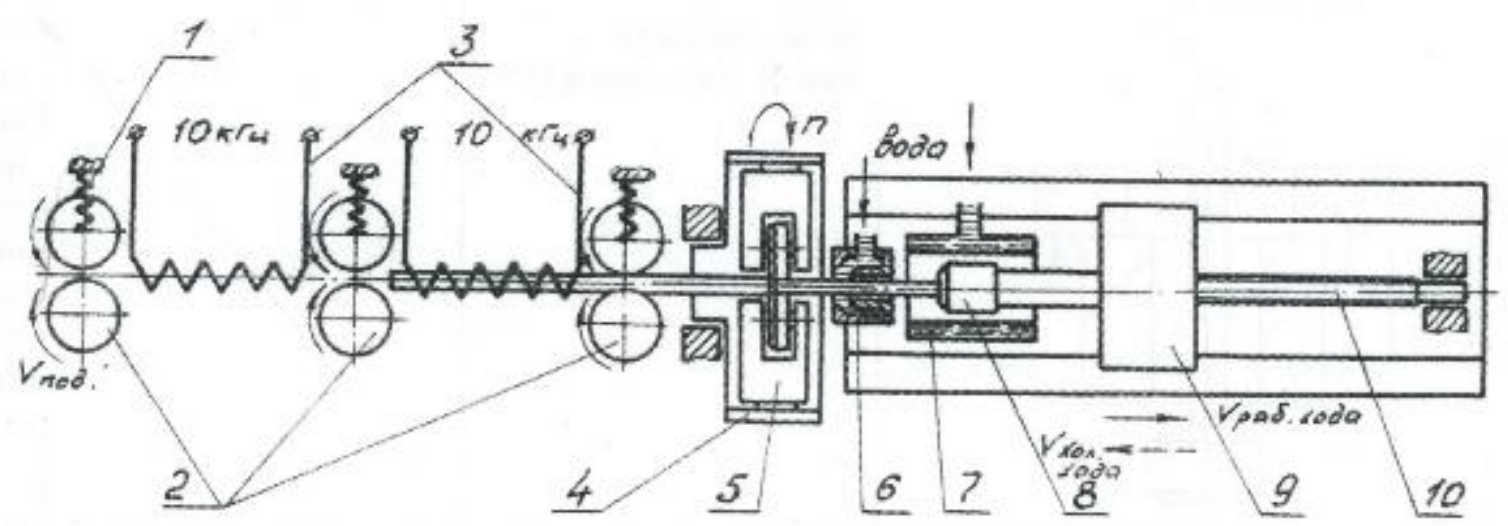

Рисунок 2. Схема опьтно-промышленной установки для производства калиброванной стали с применением ВУК TMO:

1 - пружсина; 2 - задающие ролики; 3 - индукторы нагрева; 4 - планшайба; 5 - роликовые головки; 6 форсунка; 7 -спреер; 8-захват; 9-тележка; 10 -ходовой винт.

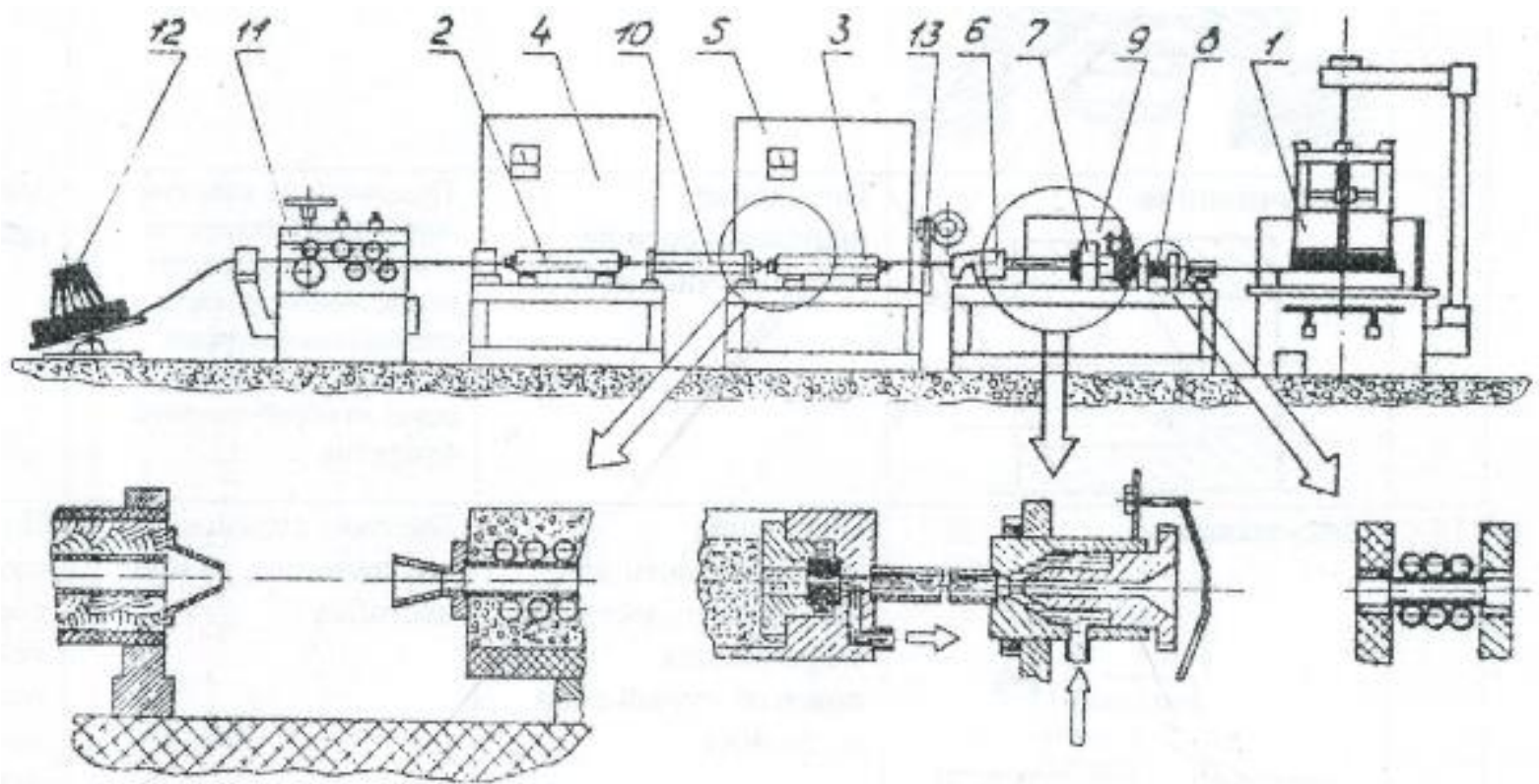

Рисунок 3. Схема установки для осуществления процесса ВУК ТМО проволоки с деформаџией в фильере: 1 - волочильный барабан; 2,3 - индукторы 1-й и 2-й ступеней нагрева; 4,5 - установки ТВЧ; 6,7 - узль деформации и охлаждения; 8 - индуктор отпуска; 10 - термостат; 11 - правильное устройство.

Технологическими параметрами ВУК ТМО, позволяющими в зависимости от назначения деталей и применяемой схемы формировать свойства упрочненного металла с широким диапазоном значений, являются: индукционный нагрев выше АC3 под деформацию, деформация с управляемой степенью, отпуск, последующий после ВУК ТМО в диапазоне 200 - 4000С в зависимости от технологии изготовления конкретной детали. Работами последних лет [5] показано, что определенным сочетанием указанных технологических параметров из всего диапазона ВУК ТМО в обрабатываемом материале возможно достижение наивысшего (из известных в настоящее время) эффекта упрочнения в стали за счет формирования наноразмерной структуры. Такое оптимальное сочетание температурно-деформационных параметров обработки, позволяющее формировать в заготовке под детали наноразмерной структуры при 
одновременном обеспечении заданных точностных характеристик металлопродукции, управляемо осуществимо на оборудовании, разработанном по указанным на рисунках 1 и 2 схемах.

Другим достоинством разработанной схемы обработки является возможность управления на установках подобного типа широким диапазоном температурно-деформационных параметров, позволяющих использовать это оборудование не только в режиме термодеформационного упрочнения, но и для производства высокоточных заготовок в виде калиброванных прутков, проволоки без упрочнения материала.

Иное конструктивное оформление термодеформационных и других силовых агрегатов по указанной технологической схеме позволяет производить длинномерные заготовки типа труб, периодического профиля, зубчатых колес с калибровкой профиля в процессе деформации и др. Такие заготовки позволяют производить из них детали по укороченной схеме механической обработки. Организация производства таких заготовок с учетом необходимой программы выпуска возможно осуществить как в калибровочных цехах металлургических, так и в заготовительных цехах машиностроительных предприятий.

Предлагаемая схема производства большого диапазона деталей изделий машиностроения позволяет значительно снизить энергозатраты на производство 1 т изделий машиностроения и суммарную трудоемкость их изготовления и, следовательно, существенно повышает производительность при изготовлении большой номенклатуры изделий.

Следует отметить, что такая технологическая схема производства деталей, суммарно решающая общую задачу металлургов и машиностроителей по снижению себестоимости изготовления изделий машиностроения, не известна в мировой практике.

В качестве примера, показывающего, что применением ВУК ТМО в технологии изготовления деталей можно не только повысить характеристики работоспособности, но и значительно упростить технологический цикл изготовления деталей на машиностроительном предприятии, приведены результаты исследований по применению упрочненной ВУК ТМО заготовки для изготовления пальцев траков гусеничной машины, работающих в условиях абразивного изнашивания.

Анализ конструкции и технологии изготовления пальцев траков показывает, что все они достаточно просты по конструкции и это позволяет использовать для их изготовления прутковую заготовку со свойствами, предъявляемыми к материалу готовой детали.

На рисунке 3 приведен чертеж пальцев, широко применяемых в гусеничных машинах для сборки гусеничной ленты. Технология их изготовления однотипна и включает следующие операции (рисунок 4a):

1. Рубка прутков на прессе на мерные заготовки;

2. Загрузка заготовками контейнера и подача их в электровысадочный автомат типа АЭ - 5III АНИТИМ; 
3. Нагрев конца заготовки (длиной до 10 мм) в электролите до температуры 1150 - 11800С. Время прохождения через электролит до высадки головки 12 - 15 с.;

4. Высадка головки и автоматический выброс пальца с головкой в контейнер;

5. Токарная обработка утолщения прутка под высаженной головкой;

6. Термическая обработка:

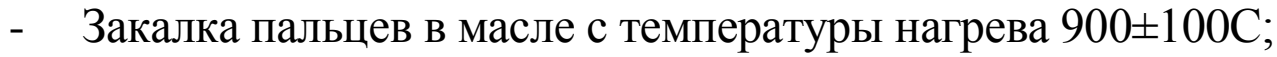

- Отпуск пальцев при T $=450$ - 5000С;

- Рихтовка пальцев;

- Контроль твердости;

7. Отпуск второго конца пальца (нагрев ТВЧ на длину $12-20$ мм при Т $=600-6500$ С в течение $5-7$ с.);

8. Рассверловка конца пальца под развальцовку.
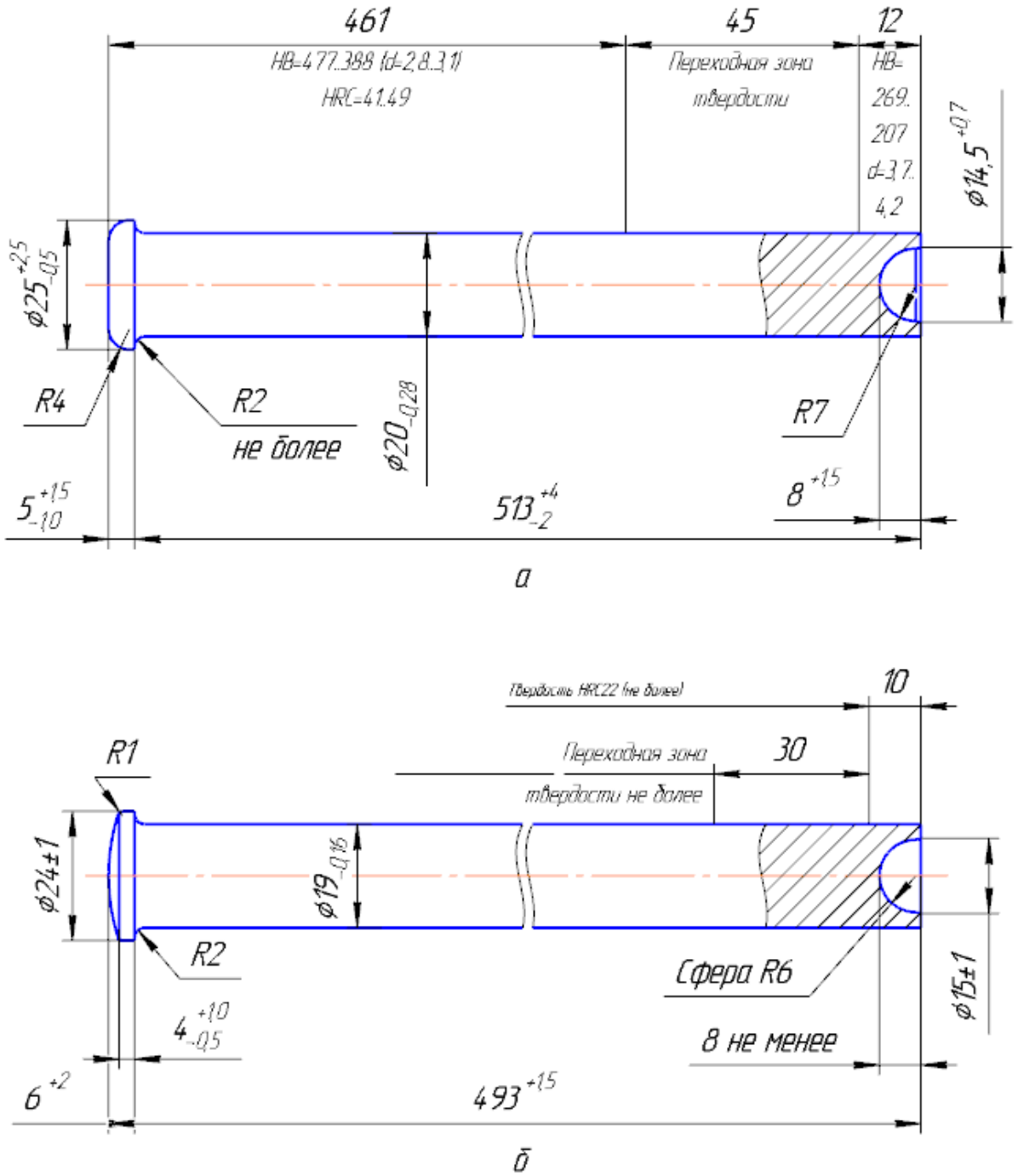

Рисунок 3. Характерные требования, предъявляемые к пальцам гусеницьь 


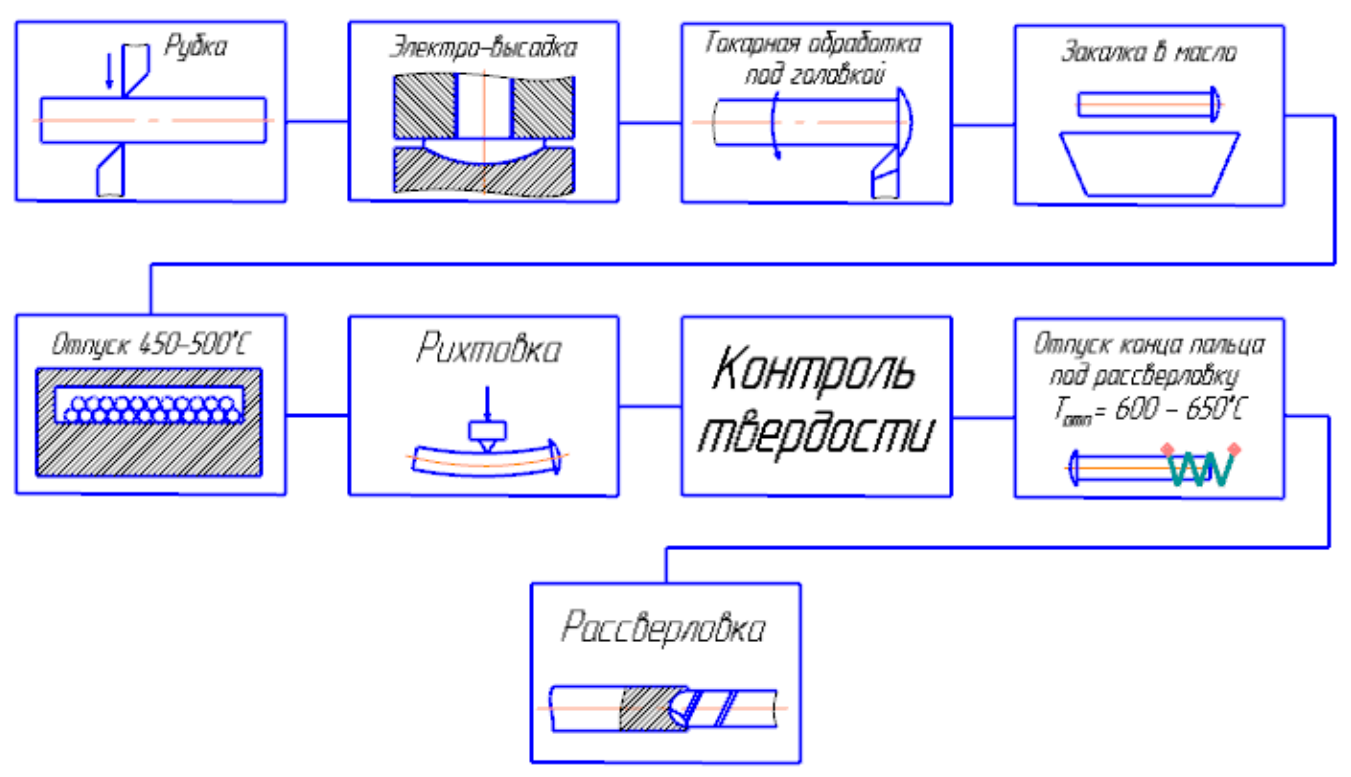

$a$

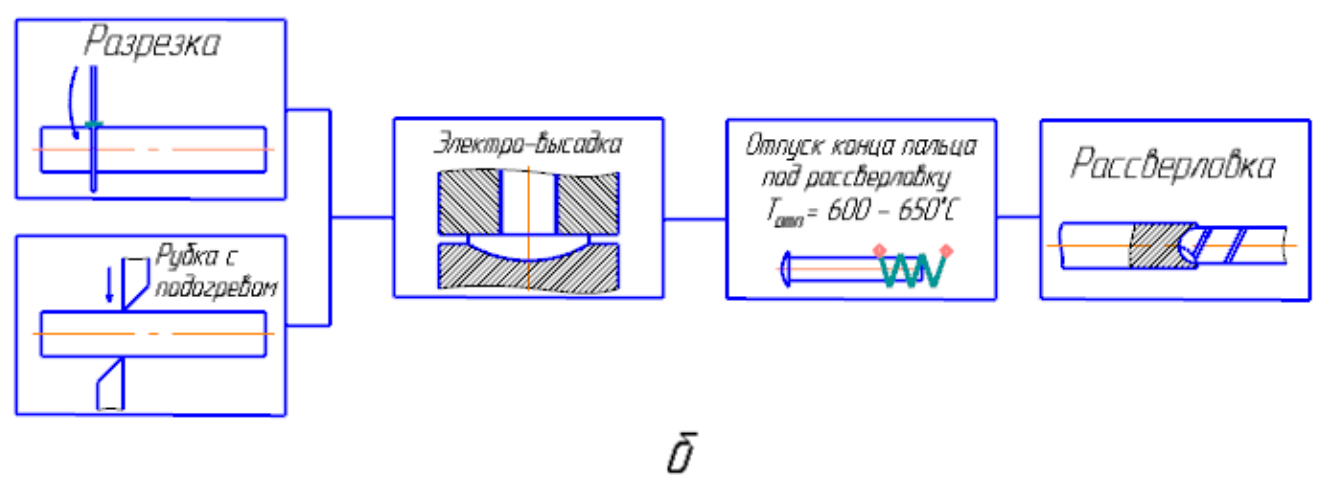

Рисунок 4. Технологические схемы изготовления пальцев по серийной технологии из калиброванного проката по ГОСТ 4543-71 (a) и по разработанной технологии с применением упрочненной ВУК ТМО заготовки (б).

Особенности заготовок после ВУК ТМО, заключающиеся в их поставке со свойствами, отвечающими по механическим и геометрическим характеристикам требованиям технических условий, предъявляемым к готовому пальцу, позволяют изменить существующую технологию (рисунок 4б):

- В связи с высокой твердостью заготовок после ВУК ТМО вводится разрезка прутков по длине на мерные заготовки вулканитовым кругом, либо рубка с применением местного индукционного подогрева участка, подлежащего разрезке;

- Так как при нагреве с высокой скоростью металл после ВУК ТМО обладает повышенной стойкостью против разупрочнения, то при высадке головки из упрочненной заготовки утолщения стержня пальца не наблюдается, в связи с чем операция токарной обработки по снятию наплыва металла под головкой - исключается; 
- Из технологического процесса полностью исключается термическая обработка (закалка, отпуск) и рихтовка пальцев;

- В связи с торможением процессов разупрочнения при отпуске металла после ВУК ТМО температура индукционного нагрева пальца под рассверловку повышается до 700 - 7500С с выдержкой 5-7 с.

Исследовалась твердость по длине пальца со стороны высаженной головки и с противоположного, отпущенного и рассверленного конца.

Отпущенная зона пальца со стороны головки со структурой троостосорбита составляет 11 мм (рисунок 5), а общая длина отпущенного стержня до зоны с твердостью металла в состоянии поставки равна $30-34$ мм. При исследовании изменения твердости после высадки головки с нагревом его в электролите отмечено также, что вследствие хорошего контакта материала пальца с охлаждаемым штампом происходит частичная подзакалка головки до твердости 47 - 48 HRC (рисунок 5а). Противоположный конец пальца, отпущенный ТВЧ под рассверловку и развальцовку (рисунок 5б) имеет одинаковую с серийными пальцами твердость и распределение ее по длине, обеспечивая технические требования: твердость на длине 10 мм от торца пальца не выше НВ 269 - 207 и длину переходной зоны от этого участка с твердостью основного металла пальца не более 30 мм. Это условие обеспечивается повышением температуры отпуска конца пальца на 50 - 700С по сравнению с серийным режимом.

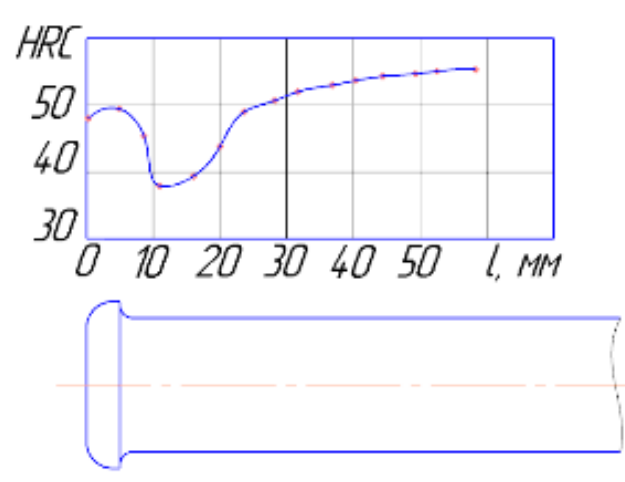

$a$
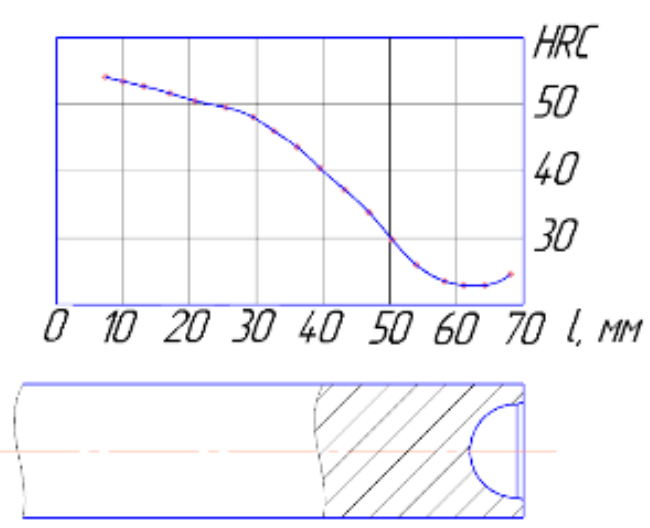

$\delta$

Рисунок 5. Твердость пальиза $a$ - после высадки головки из заготовки, упрочненной ВУК ТМО; б - после отпуска ТВЧ под развальцовку.

Проведенная работа по разработке технологии изготовления пальцев из упрочненной ВУК ТМО заготовки и исследование их качества показали возможность промышленного изготовления таких пальцев с изменением, заключающемся в сокращении технологического цикла изготовления пальцев за счет формирования в заготовке свойств по геометрическим и механическим характеристикам на уровне конструкторских требований к пальцу. Применение калиброванной упрочненной методом ВУК ТМО заготовки пальцев траков гусеничной ленты позволяет [6]: сократить технологический цикл изготовления пальцев за счет исключения операций термической, механической обработки и 
правки на заводе-изготовителе, повысить твердость и пластичность материала, что обеспечивает увеличение износостойкости в 1,6 - 1,9 раза и долговечности пальцев в 7 - 9 раз (при одинаковом с серийными пальцами уровне рабочих напряжений).

Таким образом, из всех применяемых методов технологического повышения характеристик работоспособности абразивно-изнашиваемых деталей, ВУК ТМО является не только методом, обеспечивающим комплексное улучшение износостойкости и долговечности, но и снижающим трудоемкость изготовления широко распространенных в технике деталей этого класса.

\section{Литература}

1. Бернштейн М.Л., Займовский В.А., Капуткина Л.М. Термомеханическая обработка стали. - М.: Металлургия, 1983. - 480 с.

2. Шаврин О.И., Маслов Л.Н., Скворцов А.Н. Повышение характеристик работоспособности абразивно-изнашиваемых деталей высокотемпературной упрочняюще-калибрующей термомеханической обработкой. //Контактная жесткость, износостойкость, технологическое обеспечение: Международная научно-техническая конференция, 23-24 октября 2003 г. Брянск, - Брянск, БГТУ, 2003, -с. 5-8.

3. Шаврин О.И., Маслов Л.Н., Трухачев А.В. и др. Исследование и разработка технологии производства калиброванной стали с термомеханическим упрочнением. - Сталь, 1981, №3, с. 75-78.

4. Маслов Л.Н., Шаврин О.И., Дементьев В.Б., Князев А.Г., Скворцов А.Н. Обеспечение геометрических показателей качества заготовок абразивно-изнашиваемых деталей, изготовленных с применением термомеханического упрочнения. - Заготовительное производство в машиностроении - №5, 2006. - с.33-37.

5. Шаврин О.И., Скворцов А.Н., Маслов Л.Н. Технологические и математические модели термомеханической обработки проволоки, калиброванной стали и деталей машин с формированием наноструктуры и повышенных эксплуатационных характеристик. //Современные методические материалы и технологии: 11-я международная научнотехническая конференция, 23-27 июня 2015 г., г. Санкт-Петербург.

6. Маслов Л.Н., Трухачев А.В. Термомеханическая обработка конструкционной стали $38 X \mathrm{X}$ для деталей, работающих в условиях абразивного изнашивания. //Трение и износ. - 1988. Т.9, вып. №5, -с. 910-918. 